\title{
Sistem Pakar Mendiagnosa Penyakit pada Gigi Menggunakan Metode Bayes-Forward Chaining
}

\author{
Erlangga Samudera Kencana*1, Agus Sidiq Purnomo² \\ 1,2Teknik Informatika, Universitas Mercu Buana Yogyakarta, Indonesia. \\ Email: 17111039@student.mercubuana-yogya.ac.id, ${ }^{2}$ sidiq@mercubuana-yogya.ac.id
}

\begin{abstract}
Abstrak
Gigi merupakan salah satu alat pencernaan makanan yang paling penting. Penyakit Gigi merupakan salah satu jenis penyakit yang sering dipandang ringan, namun sangat mengganggu bagi penderita penyakit tersebut, terutama saat aktivitas makan. Penyakit gigi memiliki banyak jenis dan mempunyai bentuk gejala hampir sama. Sistem pakar dapat mendeteksi penyakit. Dengan menjawab pertanyaan-pertanyaan yang terdapat di web sistem pakar oleh tenaga medis, maka dapat menentukan jenis penyakit gigi yang diderita pasien. Selain itu dibutuhkan tahapan-tahapan penelitian seperti pengumpulan data penyakit dan gejala dari tenaga medis, perancangan sistem dan perancangan database. Dengan menggunakan metode Nä̈ve Bayes yaitu menggunakan data-data seperti gejala - gejala pada umumnya yang sudah dikelompokan dan ditentukan sesuai golongan jenis penyakit gigi, dan juga hasil data diagnosa pasien, sistem pakar dapat menentukan penyakit gigi yang diderita pasien. Sehingga diharapkan dapat membantu dan memudahkan tenaga medis dalam bekerja menangani pasien dengan hasil kesesuaian 96,6\%.
\end{abstract}

Kata kunci: Nä̈ve Bayes, penyakit gigi, sistem pakar

\section{Expert System To Diagnose Dental Disease Using Bayes-Forward Chaining Method}

\begin{abstract}
Teeth are one of the most important organs of digestion. Dental disease is one type of disease that is often considered mild, but it is very disturbing for sufferers, especially when eating. Dental disease has many types and has almost the same form of symptoms. An expert system can help detect diseases. By answering questions that were entered into the expert system web by medical personnel, it can help determine the type of dental disease suffered by the patient. In addition, it is also necessary to carry out research stages such as collecting diseases and symptoms from medical personnel, system design and database design. By using the Nä̈ve Bayes method, which uses data such as symptoms in general that have been grouped and determined according to the types of dental disease, and also the results of patient diagnosis data, the expert system can help determine the dental disease suffered by the patient. Therefore, the system is expected to help and facilitate medical personnel in working with patients with $96.6 \%$ matching results.
\end{abstract}

Keywords: dental disease, expert system, Nä̈ve Bayes

\section{PENDAHULUAN}

Penyakit Gigi merupakan salah satu gangguan kesehatan yang paling banyak diderita oleh masyarakat. Makanan-makanan manis dan lengket merupakan salah satu sumber makanan bagi bakteri perusak gigi, karena makanan tersebut mudah tertinggal di sela-sela gigi. Selain makanan manis, faktor penyebab timbulnya penyakit gigi tidak lain adalah rokok yang dikonsumsi secara berlebihan. Penderita sakit gigi pada umumnya mengeluh merasakan nyeri pada gigi. Dan siapapun dapat mengalami ini tanpa terkecuali. Penyakit gigi juga bisa sebabkan oleh penyakit lain, sebagai contoh penyakit jantung. Penyakit gigi memiliki banyak jenis dan susah untuk dideteksi. Sehingga penyakit gigi bisa menjadi sangat fatal apabila tidak segera ditangani [1].

Penyakit gigi dan mulut menyebabkan penderita tidak dapat bekerja, berpikir serta beraktivitas dengan baik. Sering seseorang baru menyadari pentingnya menjaga kesehatan gigi dan mulut, ketika sudah timbul penyakitpenyakit berbahaya yang menyerang organ-organ tubuh lainnya. Salah satu penyebab rendahnya kesadaran masyarakat terhadap gigi dan mulut adalah minimnya pengetahuan kesehatan gigi dan mulut serta terbatasnya jumlah dokter gigi [2].

Pada penelitian ini menggunakan metode Forward Chaining sebagai mesin inferensi dan metode Naïve Bayes sebagai perhitungan data. Tidak hanya itu saja, dalam penelitian ini penyusun pemrograman menggunakan metode 
Incremental sebagai kedetailan mendeteksi kekurangan-kekurangan pemrograman agar program dapat berjalan dengan lancar.

Berdasarkan hal tersebut, dapat dirumuskan permasalahan: (1) Bagaimana merancang prototipe sistem pakar untuk mendiagnosa penyakit gigi menggunakan metode sistem pakar untuk mendiagnosa penyakit gigi menggunakan metode Forward Chaining dan Nä̈ve Bayes. (2) Bagaimana kinerja dari prototipe sistem pakar penyakit gigi yang digunakan. Penelitian ini bertujuan untuk: (1) Membangun prototipe sistem pakar untuk diagnosa penyakit gigi menggunakan Forward Chaining dan Naïve Bayes. (2) Mengukur kinerja kinerja dari prototipe sistem pakar penyakit gigi. Manfaat dari penelitian ini antara lain: (1) Menghasilkan prototipe sistem pakar yang dapat digunakan untuk membantu mendiagnosa penyakit gigi. (2) Mengetahui kinerja dari prototipe sistem pakar dalam mendiagnosa penyakit gigi.

\section{TINJAUAN PUSTAKA}

Penelitian tentang diagnosa penyakit kulit. Dilakukan dengan cara mengumpulkan data kriteria sebagai parameter antara lain gejala-gejala dan jenis-jenis penyakit kulit. Kemudian data-data tersebut dikelompokan ke dalam sebuah aturan yang diberi nilai bobot yang dihasilkan dari sebuah hitungan. Kemudian user menginput gejala yang dialami, dan sistem akan menghitung nilai bobot gejala, sehingga menghasilkan nilai kepastian dan hasil diagnosa. Metode yang digunakan dalam penelitian ini adalah Nä̈ve Bayes. Hasil dari penelitian ini terdapat 5 ketidakcocokan dengan diagnosis dokter dari 24 data yang diuji yang disebabkan terdapat gejala terdapat lebih dari satu penyakit. Sedangkan sistem hanya dapat mendiagnosis dengan hasil satu penyakit [3]

Penelitian tentang sistem pakar diagnosa penyakit gigi dan mulut. Sistem ini dilakukan dengan berbasis web. Selain itu metode yang digunakan Forward Chaining. Dengan adanya sistem ini, diharapkan bagi pengguna yang awam dapat mengetahui solusi dari penyakit gigi dan mulut. Selain itu memberikan pemahaman tentang penyakit gigi dan mulut sangatlah penting, sebab apabila tidak ditangani dengan cepat mengakibatkan kerusakan sehingga penyakit akan bertambah parah. Dengan aplikasi yang dapat diakses melalui device yang terhubung oleh internet ini, pemakai dapat menggunakan dimanapun dan kapanpun [4].

Penelitian tentang diagnosis penyakit kucing. Dilakukan dengan membangun berbasis sistem Android. Dilakukan dengan mengumpulkan data gejala penyakit pada kucing, yang diolah dan dihitung oleh sistem, sehingga menghasilkan data peluang dan data kepercayaan sebuah penyakit yang dialami oleh kucing. Metode yang dipakai ada 2, antara lain metode Nä̈ve Bayes dan metode Certainty Factor. Metode Nä̈ve Bayes dalam sistem ini digunakan untuk menghitung peluang kemunculan dan probabilias masing-masing penyakit dari data gejala penyakit, sedangkan metode Certainty Factor digunakan untuk memberikan nilai kepercayaan dari gejala penyakit. Hasil dari penelitian ini data yang dihasilkan metode Certainty Factor memiliki kesesuaian yang sama sehingga cocok $100 \%$, sedangkan data yang dihasilkan metode Nä̈ve Bayes terdapat 5 data uji yang tidak sesuai yang disebabkan oleh kemiripan gejala sehingga data berjalan $80 \%$ [5].

Penelitian tentang implementasi diagnosis penyakit lambung. Sebuah aplikasi web yang digunakan untuk mendeteksi penyakit pada lambung yang diolah menurut data gejala dan golongan jenis penyakit lambung sebagai kriteria. Dengan aplikasi web ini diharapkan mempermudah masyarakat untuk mendapatkan informasi awal tanpa harus pergi ke rumah sakit terlebih dahulu. Untuk metode yang digunakan dalam penelitian ini adalah metode Nä̈ve Bayes. Hasil analisa dari penelitian ini adalah berupa output nama penyakit lambung beserta persentase diagnosa [6].

Penelitian tentang diagnosa penyakit gigi. Sebuah penelitian yang menggunakan metode Nä̈ve Bayes untuk mengetahui jenis penyakit gigi yang dialami penderita. Metode ini menggunakan data training untuk mendapatkan probabilitas setiap kriteria, hasil Normalisasi nilai LikeHood tertinggi menjadi hasil diagnosa dalam penelitian ini. Dengan berbasis aturan dengan tujuan mengklasifikasi penyakit berdasarkan gejala penyakit tersebut. Penelitian dilakukan beberapa tahapan untuk memasukan inputan fakta gejala penyakit, yang kemudian sistem ini akan menghitung probabilitas prior, likehood, dan posterior. Sehingga nilai terbesar dari perhitungan posterior juga akan digunakan sebagai hasil diagnosa [1].

Penelitian tentang penyakit pada anak dibawah lima tahun. Sebuah penelitian dengan menggunakan Forward Chaining untuk mengetahui jenis penyakit pada anak di bawah lima tahun. Metode ini menggunakan bahan 36 data gejala dan 18 data penyakit sebagai data kriteria. Dalam pembuatan aplikasi dalam penelitian ini membutuhkan tiga tahap, diantaranya pengumpulan data dan informasi dari MTBS dan wawancara, pembuatan rule berdasarkan 18 penyakit, dan yang terakhir implementasi aplikasi sistem pakar berbasis android dengan fitur diagnosa penyakit, riwayat diagnosa dan kumpulan penyakit. Sehingga menghasilkan akurasi sistem yang lumayan baik [7].

Penelitian tentang konseling dan psikoterapi masalah kepribadian dramatik. Sebuah penelitian yang menggunakan 26 gejala dan 4 kategori penyakit kepribadian sebagai data kriteria yang berguna untuk mendiagnosa penyakit ini. Dengan menggunakan metode Forward Chaining untuk menganalisis masalah gangguan tersebut, 
hasil penelitian ini sangatlah memuaskan. Perbandingan hasil data uji lapangan dengan data uji program sama. Dengan adanya hasil ini membuktikan bahwa metode Forward Chaining ini, cocok digunakan untuk mendiagnosa dan mendeteksi gangguan kepribadian ini. Sehingga dengan ada sistem berbasis web ini dapat membantu masyarakat mengetahui gejala-gejala masalah kepribadian ini [8].

Penelitian tentang diagnosis penyakit hewan sapi. Sebuah sistem pakar yang menggunakan 22 data penyakit dan 62 gejala sebagai data kriteria. Penelitian ini menggunakan metode Forward Chaining untuk mendeteksi penyakit yang dialami oleh sapi sesuai gejalanya. Hasil penelitian ini sangatlah memuaskan karena berhasil menyimpulkan jenis penyakit beserta pengobatannya dan pencegahannya. Meskipun demikian penelitian ini dapat dikembangkan dengan penambahan penyakit dan gejala jika memiliki penyakit sapi yang baru [9].

Penelitian tentang diagnosis penyakit gigi dan mulut. Penelitian ini menggunakan metode Case-Based Reasoning. Penelitian ini menggunakan 9 data penyakit, 43 data gejala, dan 11 gejala baru sebagai kriteria untuk menjalankan metode tersebut guna mendiagnosis penyakit gigi dan mulut. Hasil penelitian ini kurang memuaskan karena hasil banyak yang tidak sesuai, sehingga penelitian ini perlu mengalami perbaikan [10].

Penelitian tentang identifikasi modalitas belajar siswa. Penelitian ini menggunakan metode Forward Chaining. Penelitian ini menggunakan 45 karakter modalitas, 3 anjuran modalitas, dan 3 strategi guru. Hasil dari penelitian ini sangat sukses dan mampu mengidentifikasi modalitas belajar siswa dengan jelas tanpa harus konsultasi dengan pakar atau guru Bimbingan Konseling di sekolah. Oleh karena itu sistem pakar ini bisa digunakan untuk mmbantu guru dan siswa dalam meningkatkan cara belajar siswa yang tepat [11].

Dalam penelitian ini diharapkan dapat meminimalisir masalah-masalah yang berada dalam metode Nä̈ve Bayes dengan menggunakan Forward Chaining sebagai mesin inferensi.

\section{METODE PENELITIAN}

Berikut tahapan- tahapan yang di pakai dalam metodologi dalam penelitian pada gambar 1 .

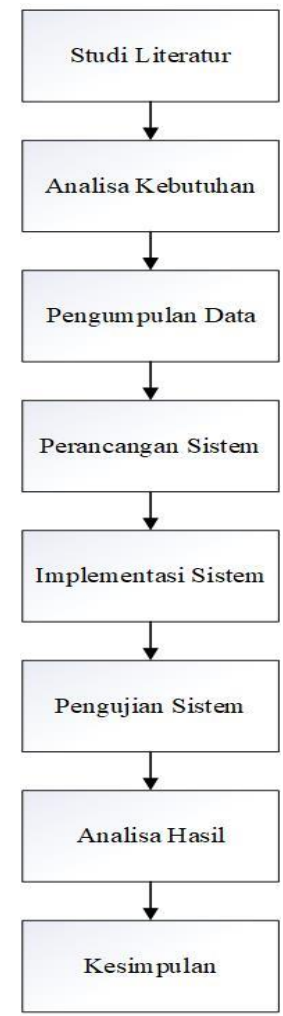

Gambar 1. Metodologi Penelitian

Dalam melaksanakan penelitian ini data ilmu kedokteran gigi dari dokter spesialis gigi maupun data dari pasien sangatlah penting. Data yang akan dikumpulkan dan dipakai dalam sebagai bahan penelitian sistem pakar terdiri dari lokasi penelitian, pakar, data gejala, data penyakit, anamnese (data pertanyaan) dan data rekamedis pasien. Dan data pakar di peroleh dari 2 lokasi yaitu Puskesmas depok 3 Yogyakarta dan Dental Center babarsari. Adapun perancangan sistem pakar yang dilakukan dan dapat dilihat pada gambar 2. 


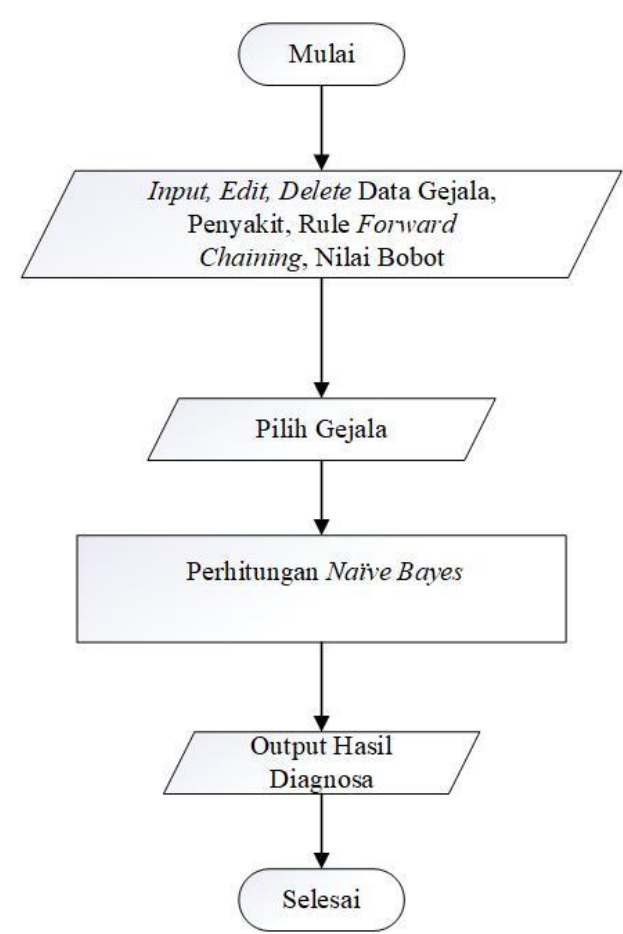

Gambar 2. Perancangan Sistem Pakar

Seadngkan perancangan database yang digunakan dalam sistem pakar dapat dilihat pada gambar 3 .

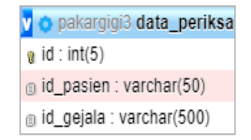

Vo pakargigi3 pekerjaan

$\checkmark$ id_pekerjaan : varchar(5) Q nama_pekerjaan : text.

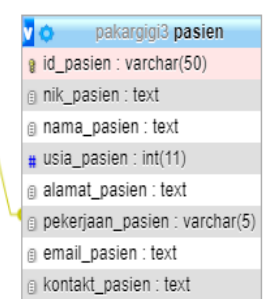

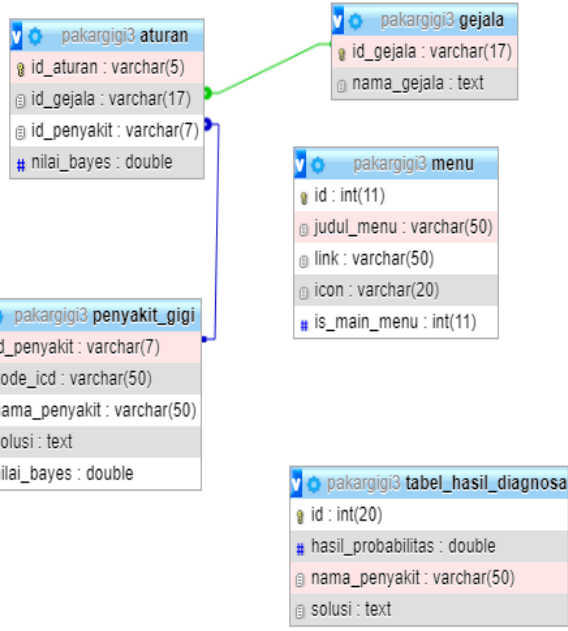

Vo. pakargigi3 tmp_final

B id : int(11)

自 id_gejala : varchar(17)

目 id_penyakit : varchar(7)

\# nilai_bayes: double

\# hasil_probabilitas : double

Gambar 3. Perancangan Database

\section{HASIL DAN PEMBAHASAN}

\subsection{Penyakit gigi}

Penyakit gigi yang di gunakan dalam penelitian ini dapat dilihat pada Tabel 1 . 
Tabel 1. Penyakit Gigi

\begin{tabular}{lll}
\hline No & Kode ICD & Nama Penyakit \\
\hline P001 & K02.0 & Karies Median \\
P002 & K04.2 & Pulpitis Irreversibel \\
P003 & K04.1 & Pulpitis Reversibel \\
P004 & K04.1 & Gangren Pulpa/ Necrosis pulpa \\
P005 & K05.0 & Gingivitis \\
P006 & K05.0 & Periodontitis \\
P007 & & Lainnya \\
\hline
\end{tabular}

\subsection{Gejala}

Gejala yang di gunakan dalam penelitian ini dapat dilihat pada Tabel 2.

Tabel 2. Gejala

\begin{tabular}{ll}
\hline Kode Gejala & Nama Gejala \\
\hline Gejala_01 & Ngilu \\
Gejala_02 & Sakit \\
Gejala_03 & Nyeri Ketika Makanan masuk \\
Gejala_04 & Lubang (Karies) pada enamel \\
Gejala_05 & Lubang (Karies) pada dentine \\
Gejala_06 & polip berdarah ketika tersentuh \\
Gejala_07 & Lubang mengenai pulpa \\
Gejala_08 & Gusi bewarna merah \\
Gejala_09 & Sakit pada gusi \\
Gejala_10 & Gingiva mengalami Pembengkakan \\
Gejala_11 & berdarah ketika sikat gigi \\
Gejala_12 & Terdapat karang gigi \\
Gejala_13 & Bau mulut (Halitosis) \\
Gejala_14 & Gusi Bengkak \\
Gejala_15 & Gusi Merah gelap \\
Gejala_16 & Sakit Sepanjang Rahang \\
Gejala_17 & Gigi Tanggal (Lepas) \\
Gejala_18 & Lainnya \\
\hline
\end{tabular}

\subsection{Data Aturan Forward Chaining}

Tabel 3. Tabel Forward Chaining

\begin{tabular}{|c|c|c|c|c|c|c|c|c|}
\hline No & Gejala & P001 & P002 & P003 & P004 & P005 & P006 & P007 \\
\hline 1 & Gejala_01 & & $\checkmark$ & $\checkmark$ & & & & \\
\hline 2 & Gejala_02 & & & & $\checkmark$ & & & \\
\hline 3 & Gejala_03 & & & $\checkmark$ & & & & \\
\hline 4 & Gejala_04 & $\checkmark$ & $\checkmark$ & & & & & \\
\hline 5 & Gejala_05 & $\checkmark$ & & & & & & \\
\hline 6 & Gejala_06 & & & & $\checkmark$ & & & \\
\hline 7 & Gejala_07 & & & $\checkmark$ & $\checkmark$ & & & \\
\hline 8 & Gejala_08 & & & & & $\checkmark$ & & \\
\hline 9 & Gejala_09 & & & & $\checkmark$ & $\checkmark$ & & \\
\hline 10 & Gejala_10 & & & & & $\checkmark$ & & \\
\hline 11 & Gejala_11 & & & & & $\checkmark$ & & \\
\hline 12 & Gejala_12 & & & & & $\checkmark$ & $\checkmark$ & \\
\hline 13 & Gejala_13 & & & & & $\checkmark$ & $\checkmark$ & \\
\hline 14 & Gejala_14 & & & & & $\checkmark$ & & \\
\hline 15 & Gejala_15 & & & & & & $\checkmark$ & \\
\hline 16 & Gejala_16 & & & & & & $\checkmark$ & \\
\hline 17 & Gejala_17 & & & & & & $\checkmark$ & \\
\hline 18 & Gejala_18 & & & & & & & $\checkmark$ \\
\hline
\end{tabular}


Dalam penelitian ini dibutuhkan metode Forward Chaining sebagai mesin inferensi untuk membuat rule. Data aturan Forward Chaining sederhana dapat dibuat tabel seperti pada Tabel 3 dan konversi Forward Chaining ke dalam nilai dapat dilihat pada Tabel 3.

Tabel 4. Konversi Forward-Chaining ke dalam data nilai

\begin{tabular}{|c|c|c|c|c|c|c|c|c|}
\hline No & Gejala & P001 & P002 & P003 & P004 & P005 & P006 & P007 \\
\hline 1 & Gejala_01 & & 0,3 & 0,1 & & & & \\
\hline 2 & Gejala_02 & & & & 0,05 & & & \\
\hline 3 & Gejala_03 & & & 0,4 & & & & \\
\hline 4 & Gejala_04 & 0,5 & 0,7 & & & & & \\
\hline 5 & Gejala_05 & 0,5 & & & & & & \\
\hline 6 & Gejala_06 & & & & 0,15 & & & \\
\hline 7 & Gejala_07 & & & 0,5 & 0,6 & & & \\
\hline 8 & Gejala_08 & & & & & 0,1 & & \\
\hline 9 & Gejala_09 & & & & 0,2 & 0,15 & & \\
\hline 10 & Gejala_10 & & & & & 0,2 & & \\
\hline 11 & Gejala_11 & & & & & 0,1 & & \\
\hline 12 & Gejala_12 & & & & & 0,15 & 0,1 & \\
\hline 13 & Gejala_13 & & & & & 0,2 & 0,1 & \\
\hline 14 & Gejala_14 & & & & & 0,1 & & \\
\hline 15 & Gejala_15 & & & & & & 0,2 & \\
\hline 16 & Gejala_16 & & & & & & 0,3 & \\
\hline 17 & Gejala_17 & & & & & & 0,3 & \\
\hline 18 & Gejala_18 & & & & & & & 1 \\
\hline
\end{tabular}

\subsection{Kecocokan}

Berikut adalah data kecocokan penilaian secara manual pada Tabel 5.

Tabel 5. Tabel kecocokan

\begin{tabular}{|c|c|c|c|c|}
\hline No & Pasien & Hasil Diagnosis Dokter & Hasil Sistem & $\begin{array}{l}\text { Kecocokan hasil dokter dan } \\
\text { hasil sistem }\end{array}$ \\
\hline 1 & Pasien_01 & k04.1(necrosis pulpa) & k04.1(necrosis pulpa) & sesuai \\
\hline 2 & Pasien_02 & k05.(gingivitis \& periodontitis) & k05.Periodontitis & sesuai \\
\hline 3 & Pasien_03 & k05.(gingivitis \& periodontitis) & k05.Periodontitis & sesuai \\
\hline 4 & Pasien_04 & k05.(gingivitis \& periodontitis) & k05.Gingivitis & sesuai \\
\hline 5 & Pasien_05 & k05.(gingivitis \& periodontitis) & k05.Gingivitis & sesuai \\
\hline 6 & Pasien_06 & k04.1(necrosis pulpa) & k04.1(necrosis pulpa) & sesuai \\
\hline 7 & Pasien_07 & k02(Dental Karies) & k02(Dental Karies) & sesuai \\
\hline 8 & Pasien_08 & Impacted teeth & lainnya & sesuai \\
\hline 9 & Pasien_09 & Embedden and impacted teeth & lainnya & sesuai \\
\hline 10 & Pasien_10 & k04.1(necrosis pulpa) & lainnya & sesuai \\
\hline 11 & Pasien_11 & k04.1(necrosis pulpa) & k04.1(necrosis pulpa) & sesuai \\
\hline 12 & Pasien_12 & $\mathrm{k} 04.1$ (necrosis pulpa) & k04.1(necrosis pulpa) & sesuai \\
\hline 13 & Pasien_13 & k04.1(necrosis pulpa) & $\mathrm{k} 04.1$ (necrosis pulpa) & sesuai \\
\hline 14 & Pasien_14 & k04.1(necrosis pulpa) & k04.1(necrosis pulpa) & sesuai \\
\hline 15 & Pasien_15 & k02(Dental Karies) & k02(Dental Karies) & sesuai \\
\hline 16 & Pasien_16 & $\begin{array}{c}\text { Disorders of tooth development } \\
\text { and eruption }\end{array}$ & lainnya & sesuai \\
\hline 17 & Pasien_17 & K05 gingivitis & k04.1(necrosis pulpa) & Tidak sesuai \\
\hline 18 & Pasien_18 & K05 Periodontitis & K05 Periodontitis & sesuai \\
\hline 19 & Pasien_19 & k05.(gingivitis \& periodontitis) & k05.Gingivitis & sesuai \\
\hline 20 & Pasien_20 & k05.(gingivitis \& periodontitis) & k05.Gingivitis & sesuai \\
\hline 21 & Pasien_21 & $\begin{array}{c}\text { Disorders of tooth development } \\
\text { and eruption }\end{array}$ & lainnya & sesuai \\
\hline 22 & Pasien_22 & k05.(gingivitis \& periodontitis) & k05.Gingivitis & sesuai \\
\hline 23 & Pasien_23 & Disorders of tooth development & lainnya & sesuai \\
\hline
\end{tabular}




\begin{tabular}{|c|c|c|c|c|}
\hline 24 & Pasien_24 & Embedden and impacted teeth & lainnya & sesuai \\
\hline 25 & Pasien_25 & Embedden and impacted teeth & lainnya & sesuai \\
\hline 26 & Pasien_26 & $\begin{array}{c}\text { Disorders of tooth development } \\
\text { and eruption }\end{array}$ & lainnya & sesuai \\
\hline 27 & Pasien_27 & $\begin{array}{c}\text { Disorders of tooth development } \\
\text { and eruption }\end{array}$ & lainnya & sesuai \\
\hline 28 & Pasien_28 & K05 Periodontitis & K05 Periodontitis & sesuai \\
\hline 29 & Pasien_29 & k04.1(necrosis pulpa) & k04.1(necrosis pulpa) & sesuai \\
\hline 30 & Pasien_30 & k05.(gingivitis \&periodontitis) & k05.Gingivitis & sesuai \\
\hline
\end{tabular}

Dari 30 data yang diujikan dalam sistem ini, terdapat 29 data yang sesuai dengan hasil analisis dokter dan 1 data yang tidak sesuai dengan analisis dokter Sehingga tingkat kesesuaian data tersebut

$$
(29 \div 30) \times 100 \%=96.67 \%
$$

\subsection{Hasil Perhitungan}

Dari Tabel 5 pasien_28 diketahui menderita gejala_12, gejala_13, gejala_16 di ketahui bobot gejala penyakit pada penyakit gingivitis dan periodontitis seperti yang ditunjukan pada Tabel 6 dan Tabel 7.

\begin{tabular}{cc}
\multicolumn{2}{c}{ Tabel 6. Tabel Gingivitis } \\
\hline Gingivitis & Bobot \\
\hline Gejala_12 & 0.15 \\
Gejala_13 & 0.2 \\
\hline
\end{tabular}

Untuk total semesta $0.15+0.2=0.35$

Sehingga untuk gejala_12 dan gejala_13 pada penyakit gingivitis memiliki Phi

Gejala_12 $=0.15 \div 0.35=0.429$

Gejala_13 $=0.2 \div 0.35=0.571$

Mencari Semesta $\mathrm{P}(\mathrm{Hi})=(\mathbf{0 . 1 5} \times \mathbf{0 . 4 2 9})+(\mathbf{0 . 2} \times \mathbf{0 . 5 7 1})=0.179$

Sehingga $\mathrm{P}(\mathrm{Hi} \mid \mathrm{E})$

Gejala_12 $=(0.15 \times 0.429) \div 0.179=0.054$

Gejala_13 $=(0.2 \times 0.571) \div 0.179=0.128$

Sehingga Total $=0.054+0.128=0.182$

Sedangkan untuk gejala_12, gejala_13, gejala_16

\begin{tabular}{cc}
\multicolumn{2}{c}{ Tabel 7. Tabel Periodontitis } \\
\hline Periodontitis & Bobot \\
\hline Gejala_12 & 0.1 \\
Gejala_13 & 0.1 \\
Gejala_16 & 0.3 \\
\hline
\end{tabular}

Sehingga total semesta $0.1+01+0.3=0.5$

Sehingga untuk gejala_12 dan gejala_13 pada penyakit gingivitis memiliki Phi

Gejala_12 $=0.1 \div 0.5=0.2$

Gejala_13 $=0.1 \div 0.5=0.2$

Gejala_16 $=0.3 \div 0.5=0.6$

Mencari Semesta $\mathrm{P}(\mathrm{Hi})=(\mathbf{0 . 1} \times \mathbf{0 . 2})+(\mathbf{0 . 1} \times \mathbf{0 . 2})+(\mathbf{0 . 3} \times \mathbf{0 . 6})=\mathbf{0 . 2 2}$

Sehingga $\mathrm{P}(\mathrm{Hi} \mid \mathrm{E})$

Gejala_12 $=(0.1 \times 0.2) \div 0.22=0.009$

Gejala_13 $=(0.1 \times 0.2) \div 0.22=0.009$

Gejala_16 $=(0.3 \times 0.6) \div 0.22=0.245$

Sehingga Total $=0.009+0.009+0.245=0.264$

kesimpulan Max (Gingivitis, Periodontitis) $=\operatorname{Max}(0.182,0.264)=\mathbf{0 . 2 6 4}$.

Dari data kesimpulan maka diketahui bahwa pasien_28 mengalami penyakit Periodontitis dengan besar

$$
0.264 \times 100 \%=26.4 \%
$$




\section{KESIMPULAN}

Kesimpulan yang dapat di ambil, dari penelitian yang sudah dilakukan sebagai berikut yaitu dari 30 data yang di sudah di uji terdapat 29 data yang sesuai dengan analisa dokter dan 1 data yang tidak sesuai dengan analisa dokter sehingga total tingkat kesesuaiannya adalah 96,67\%. Sistem pakar ini dapat digunakan untuk pekerja medis gigi karena di sistem ini dapat di atur dan di sesuaikan, juga di kembangkan sesuai keinginan yang dibutuhkan untuk diagnosa penyakit gigi.

\section{DAFTAR PUSTAKA}

[1] Y. Yuliyana dan A. S. R. M. Sinaga, "Sistem Pakar Diagnosa Penyakit Gigi Menggunakan Metode Naive Bayes," Fountain of Informatics, Vol. 4, No. 1, ISSN : 2541-4313, pp. 19-23, 2019.

[2] H. S. Arfajsyah, I. Permana dan N. F. Salisah, "SISTEM PAKAR BERBASIS ANDROID UNTUK DIAGNOSA PENYAKIT GIGI DAN MULUT," Jurnal Ilmiah Rekayasa dan Manajemen Sistem Informasi, Vol. 4, No. 2, Agustus, e-ISSN : 2502-8995, p-ISSN : 2460-8181, pp. 110-117, 2018.

[3] M. I. Rizki, "SISTEM PAKAR DIAGNOSA PENYAKIT KULIT MENGGUNAKAN NAIVE BAYES BERBASIS WEB,” Jurnal Transit, Vol. 8, No. 4,Agustus ,ISSN : 2302-2709, pp. 27-34, 2020.

[4] Tuslaela dan D. Permadi, "SISTEM PAKAR DIAGNOSA PENYAKIT GIGI DAN MULUT BERBASIS WEB DENGAN METODE FORWARD CHAINING," Jurnal Prosisko, Vol. 5, No. 1, Maret e-ISSN: 25979922, p-ISSN: 2406-7733, pp. 17-26, 2018.

[5] A. A. S. Nugraha, N. Hidayat dan L. Fanani, "Sistem Pakar Diagnosis Penyakit Kucing Metode Naive Bayes - Certainty Factor Berbasis Android," Jurnal Pengembangan Teknologi Informasi dan Ilmu Komputer, Vol. 2, No. 2,Februari ,e-ISSN : 2548-964X, pp. 650-658, 2018.

[6] T. P. Wicaksono, N. Hidayat dan B. Rahayudi, "Implementasi Metode Naive Bayes Pada Diagnosis Penyakit Lambung," Jurnal Pengembangan Teknologi Informasi dan Ilmu Komputer, Vol. 3, No. 1, Januari, e-ISSN: 2548-964X, pp. 227-232, 2019.

[7] B. F. Yanto, I. Werdiningsih dan E. Purwanti, “Aplikasi Sistem Pakar Diagnosa Penyakit Pada Anak Bawah Lima Tahun Menggunakan Metode Forward Chaining," Journal of Information Systems Engineering and Business Intelligence, Vol. 3, No. 1, April, e-ISSN: 2443-2555, pp. 61-67, 2017.

[8] J. Nasir dan Jahro, "SISTEM PAKAR KONSELING DAN PSIKOTERAPI MASALAH KEPRIBADIAN DRAMATIK MENGGUNAKAN METODE FORWARD CHAINING BERBASIS WEB,” RABIT: Jurnal Teknologi dan Sistem Informasi Univrab, Vol. 03, No. 1, Januari, ISSN cetak: 2477-2062, ISSN online: 2502-891X, pp. 35-46, 2018.

[9] A. M. Fahmy dan I. P. S. J. Y. Ningrum, "SISTEM PAKAR DIAGNOSIS PENYAKIT HEWAN SAPI DENGAN METODE FORWARD CHAINING," semanTIK, Vol. 4, No. 2, Juli-Desember, ISSN: 2502-8928 (Online), pp. 111-120, 2018.

[10] C. Nas, "Sistem Pakar Diagnosa Penyakit Gigi Dan Mulut Menggunakan Metode Case-Based Reasoning," JURNAL DIGIT, Vol. 9, No. 2, November, ISSN: 2088-589X, pp. 202-214, 2019.

[11] A. Kurniawan, Sumijan dan N. Jufriadif, "Sistem Pakar Identifikasi Modalitas Belajar Siswa Menggunakan Metode Forward Chaining," JURNAL RESTI (Rekayasa Sistem dan Teknologi Informasi), Vol. 3, No. 3, Desember, ISSN Media Elektronik: 2580-0760, pp. 518-523, 2019. 